Article

\title{
Pharmacological Inhibition of Caspase-8 Suppresses Inflammation-Induced Angiogenesis in the Cornea
}

\author{
Yunzhe Tian ${ }^{+}{ }^{+}, \mathrm{He} \mathrm{Li}^{\dagger}$, Xiuxing Liu, Lihui Xie, Zhaohao Huang, Weihua Li, Zhuang Li, \\ Yuan Pan, Xiaoqing Chen and Wenru Su * \\ State Key Laboratory of Ophthalmology, Zhongshan Ophthalmic Center, Sun Yat-sen University, \\ 528400 Guangzhou, China; tianyunzhe@gzzoc.com (Y.T.); lihe25@mail2.sysu.edu.cn (H.L.); \\ liuxx65@mail2.sysu.edu.cn (X.L.); xielh29@mail2.sysu.edu.cn (L.X.); huangzhh73@mail2.sysu.edu.cn (Z.H.); \\ liweihua@gzzoc.com (W.L.); lizh258@mail2.sysu.edu.cn (Z.L.); panyuan@gzzoc.com (Y.P.); \\ chenxiaoqing@gzzoc.com (X.C.) \\ * Correspondence: suwr3@mail.sysu.edu.cn; Tel./Fax: +86-20-8733-0402 \\ + These authors contributed equally to this work.
}

Received: 19 October 2019; Accepted: 26 January 2020; Published: 31 January 2020

check for updates

\begin{abstract}
Inflammation-induced angiogenesis is closely related to many diseases and has been regarded as a therapeutic target. Caspase- 8 has attracted increasing attention for its immune properties and therapeutic potential in inflammatory disorders. The aim of our study is to investigate the clinical application of pharmacological inhibition of caspase- 8 and the underlying molecular mechanisms in inflammation-induced angiogenesis in the cornea. A model of alkali burn (AB)-induced corneal neovascularization (CNV) in C57BL/6 wild-type (WT) mice and toll-like receptor 4 knockout $\left(\mathrm{Tlr} 4^{--}\right.$) mice was used. We found that $\mathrm{AB}$ increased caspase- 8 activity and the pharmacological inhibition of caspase-8 exerted substantial inhibitory effects on $\mathrm{CNV}$, with consistent decreases in caspase- 8 activity, inflammatory cell infiltration, macrophage recruitment and activation, VEGF-A, TNF- $\alpha$, IL-1 $\beta$, MIP-1, and MCP-1 expression in the cornea. In vitro, caspase- 8 mediated TLR4-dependent chemokines and VEGF-A production by macrophages. The TLR4 knockout significantly alleviated CNV, suppressed caspase-8 activity and downregulated expression of inflammatory cytokines and chemokines after AB. Taken together, these findings provide the first demonstration that the pharmacological inhibition of caspase- 8 suppresses inflammation-induced angiogenesis and support the use of a pharmacological caspase-8 inhibitor as a novel clinical treatment for $\mathrm{CNV}$ and other angiogenic disorders.
\end{abstract}

Keywords: angiogenesis; corneal neovascularization; caspase-8; macrophage

\section{Introduction}

Angiogenesis is a fundamental process in growth. It is also vital for the pathogenesis of inflammation, cancer, atherosclerosis, rheumatoid arthritis, and ocular vascular diseases, such as diabetic retinopathy, age-related macular degeneration, and corneal neovascularization (CNV) [1-7]. Angiogenesis inhibition has been regarded as a therapeutic approach to treat these diseases [8-13]. Postnatal angiogenesis occurrence is usually associated with inflammation [1]. However, a deeper understanding of the molecular mechanisms that regulate inflammation-induced angiogenesis is needed, as are safe and effective methods of inhibiting angiogenesis.

Caspase-8, a member of caspase family with a well-characterized role in initiating cell apoptosis, has attracted increasing attention due to its immune properties [14-16]. It is a zymogen composed of an $\mathrm{N}$-terminal prodomain and a C-terminal catalytic domain. Sequence Ile-Glu-Thr-Asp (IETD) can combine with caspase-8, which results in suppression of caspase-8 activity [17]. Several recent studies have demonstrated that caspase- 8 plays an important role in the promotion of neuroinflammation, 
T-cell function, and cancer-related inflammation [18-21]. Furthermore, caspase- 8 has recently been reported to mediate the activation of the Nod-like receptor family pyrin domain-containing 3 (NLRP3) inflammasome, comprising the NLRP3 scaffold, apoptosis-associated speck-like protein containing CARD (ASC) and caspase-1, which participates in various diseases, including autoimmune disorders, type 2 diabetes, atherosclerosis, gout, and obesity [15,22-24]. Our group's most recent study found that caspase- 8 is crucial in lymphangiogenesis and allograft rejection [25]. The pharmacological inhibition of caspase-8 repressed these pathological processes [25]. Moreover, Giulia et al. demonstrated that caspase-8 contributes to angiogenesis and growth in glioblastoma [26]. However, the involvement of caspase- 8 in inflammation-associated angiogenesis and the underlying mechanisms are not yet clear.

Because the normal cornea lacks vessels and is convenient for experimental operation, it is an ideal system to investigate angiogenesis $[27,28]$. Furthermore, angiogenesis plays a key role in corneal disorders, such as corneal burn and virus infection [29-31]. Corneal alkali burn (AB) therefore serves as an ideal model to study inflammation-induced angiogenesis [32,33]. In our study, we used a mouse model of corneal AB to probe the application of a pharmacological caspase- 8 inhibitor and the involved mechanisms in inflammatory CNV.

\section{Materials and Methods}

\subsection{Animals}

Total 180 adult male mice (six to eight weeks old), weighting 20-25 g were used in this study. 144 C57BL/6 wild-type (WT) mice were obtained from the Guangdong Medical Lab Animal Center. 36

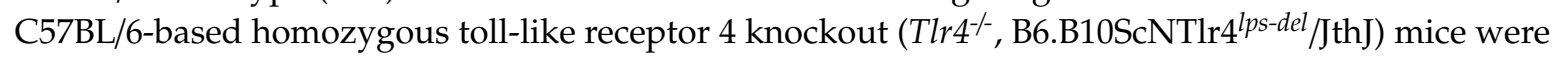
purchased from the Model Animal Research Center of Nanjing University. The animals were housed under specific pathogen-free (SPF) conditions with a 12-h light/dark cycle and stable temperature $\left(23^{\circ} \mathrm{C} \pm 2{ }^{\circ} \mathrm{C}\right)$ and humidity $(55 \% \pm 10 \%)$. All animal experiments were approved by the Institutional Animal Care and Use Committee of the Zhongshan Ophthalmic Center at Sun Yat-Sen University (No. 2017-094). The procedures were carried out according to the ARVO Statement for the Use of Animals in Ophthalmic and Vision Research.

\subsection{Mouse Model of Corneal AB}

The mouse model of corneal $\mathrm{AB}$ used here was performed by a slight modification previously described [34]. Briefly, a round piece of filter paper $(2 \mathrm{~mm}$ in diameter) soaked with $5 \mu \mathrm{L}$ of $\mathrm{NaOH}(1 \mathrm{M})$ was placed onto the right central cornea of each mouse for $30 \mathrm{~s}$. Then, the cornea was rinsed extensively with $30 \mathrm{~mL}$ of sterile saline solution. Z-IETD-fmk is a cell-permeable, selective irreversible inhibitor of caspase-8 [17]. Z-IETD-fmk ( $20 \mu \mathrm{M}, 40 \mu \mathrm{M}$, or $100 \mu \mathrm{M}$, Selleck, Houston, TX, USA) dissolved in dimethyl sulfoxide (DMSO) and diluted with saline solution was used [35]. The alkali-injured eye was topically treated with vehicle or the Z-IETD-fmk solution $(5 \mu \mathrm{L})$ four times per day for 14 days.

\subsection{Observation and Quantification of $C N V$}

The eyes of the model mice (six mice/group) were examined by a slit-lamp microscopy (Zeiss, Jena, Germany), and photos were captured by a digital camera (Topcon, Tokyo, Japan) 3, 7, and 14 days after corneal AB. Macroscopic assessments were performed by two observers (technicians of animal experimental center) who have suitable experiences. They are not authors without prior knowledge of the allocation of the animals. According to previous studies, the percentage of $\mathrm{CNV}$ covered area $(A \%)$ was quantified by the following formula: $A \%=C / 12 \times 3.1416\left[r^{2}-(r-l)^{2}\right] \times 100 \%(C$ : the clock hours of CNV coverage of the cornea, $l$ : the average length of the vessels sprouted at each clock hour, and $r$ : the radius of the mouse cornea, $r=1.5 \mathrm{~mm}$ ) [36,37]. 


\subsection{Histological Assessment of Mouse Eyes}

Mice were euthanized on day 7 after corneal AB, and injured eyes were placed in $10 \%$ neutral buffered formalin at $25{ }^{\circ} \mathrm{C}$ for $24 \mathrm{~h}$ and then paraffin-embedded after dehydration with an ethanol gradient. Sagittal sections $(4 \mu \mathrm{m})$ were stained with hematoxylin and eosin $(\mathrm{H} \& \mathrm{E})$. For each sample, three planes were selected evenly within pupillary zone. Subsequently, three sections were selected from each plane. The inflammatory cells (identified by nuclear and cellular morphology from the local corneal cells) in the corneal stroma were counted manually at 20× magnification in five different fields of each H\&E staining section. All the histological assessments were done as blind studies by the same two observers [24].

\subsection{Immunofluorescence}

Mice were sacrificed on day 7 after corneal AB for F4/80 immunostaining and on day 14 for CD31 immunostaining. The eyes were removed, fixed with $4 \%$ paraformaldehyde (PFA) overnight at $4{ }^{\circ} \mathrm{C}$, and embedded in OCT. Sagittal sections $(8 \mu \mathrm{m})$ were cut and blocked with $5 \%$ bovine serum albumin (BSA) in a Tris-buffered saline (TBS) buffer for $1 \mathrm{~h}$ at room temperature. Then, the sections were incubated with rat anti-F4/80 (Cat. No. Ab6640, 1:100, Abcam, Cambridge, UK) or rabbit anti-CD31 (Cat. No. Ab28364,1:50, Abcam) primary antibody overnight at $4{ }^{\circ} \mathrm{C}$ and further incubated with goat-anti-rat Alexa Fluor 555 (Cat. No. 4417, 1:1000, Cell Signaling Technology (CST), Danvers, MA, USA) or goat-anti-rabbit Alexa Fluor 555 (Cat. No. 4413, 1:1000, CST) secondary antibody for $1 \mathrm{~h}$ at room temperature. After counterstaining with DAPI (Abcam), the sections were examined with a fluorescence microscope (Nikon, Tokyo, Japan). We recognized the CD $31^{+} \mathrm{DAPI}^{+}$or F4/80 ${ }^{+} \mathrm{DAPI}^{+}$ double immunostaining cells in the corneal stroma and count them at $20 \times$ magnification in five different fields of each immunostaining section manually. For each sample, three planes were selected evenly within the pupillary zone. Subsequently, three sections were selected from each plane. The counting work was all performed by the same two observers not aware of the experimental design and groups of study [25].

\subsection{Cell Culture and Treatment}

RAW264.7 (Zhong Qiao Xin Zhou Biotechnology, Shanghai, China), a murine macrophage cell line, was cultured in Dulbecco's modified Eagle's medium (DMEM) containing 10\% fetal bovine serum (FBS) and $1 \%$ L-glutamine at $37{ }^{\circ} \mathrm{C}$ in a $5 \% \mathrm{CO}_{2}$ atmosphere. Cells were pretreated with or without Z-IETD-fmk $(10 \mu \mathrm{M})$ for $2 \mathrm{~h}$ and then stimulated with lipopolysaccharide (LPS, a TLR4 agonist, $100 \mathrm{ng} / \mathrm{mL}$ ) for $8 \mathrm{~h}$ (for mRNA analysis) or $16 \mathrm{~h}$ (for caspase activity analysis) [25]. For cell viability, macrophages were treated with LPS and Z-IETD-fmk $(1 \mu \mathrm{M}, 5 \mu \mathrm{M}, 10 \mu \mathrm{M}, 20 \mu \mathrm{M}$, or $40 \mu \mathrm{M})$ for $24 \mathrm{~h}$ and assessed using a Trypan blue staining assay.

\subsection{Real-Time Quantitative PCR}

Total RNA was extracted from corneal tissue or cells lysates by using the RNA-Quick Purification Kit (Yishan Biotechnology, Shanghai, China), quantified with a NanoDrop spectrophotometer (Thermo, Waltham, MA, USA), and reverse transcribed into cDNA using HiScript II Q RT SuperMix for qPCR (Vazyme Biotechnology, Nanjing, China). The mRNA level was then determined by real-time PCR using ChamQ SYBR Color qPCR Master Mix (Vazyme Biotechnology). The relative changes in mRNA expression were determined by normalizing to the expression of GAPDH using the $2^{-\Delta \Delta C t}$ method. The primer sequences were as follows: GAPDH forward, 5' -TGACCTCAACTACATGGTCTACA-3' and reverse, 5' -CTTCCCATTCTCGGCCTTG-3' ; vascular endothelial growth factor-A (VEGF-A) forward, 5'-GCACATAGAGAGAATGAGCTTCC-3' and reverse, 5'-CTCCGCTCTGAACAAGGCT-3'; tumor necrosis factor alpha (TNF- $\alpha$ ) forward, 5'-CAGGCGGTGCCTATGTCTC-3' and reverse, 5' -CGATCACCCCGAAGTTCAGTAG-3'; interleukin-1 beta (IL-1 $\beta$ ) forward, 5' -TTCAGGCAGGCAGTATCACTC-3' and reverse, 5' -GAAGGTCCACGG 


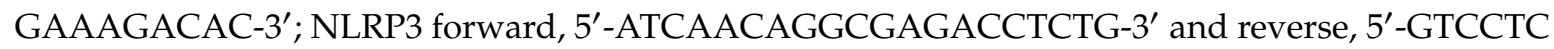
CTGGCATACCATAGA-3'; ASC forward, 5'-GACAGTGCAACTGCGAGAAG-3' and reverse, 5'-CGACTCCAGATAGTAGCTGACAA-3'; macrophage inflammatory protein-1 (MIP-1) forward, 5'-TTCTCTGTACCATGACACTCTGC-3' and reverse, 5'-CGTGGAATCTTCCGGCTGTAG-3'; monocyte chemoattractant protein-1 (MCP-1) forward, $5^{\prime}$-TTAAAAACCTGGATCGGAACCAA- $3^{\prime}$ and reverse, 5'-GCATTAGCTTCAGATTTACGGGT-3'; TLR4 forward, 5'-ATGGCATGGCTTAC ACCACC- $3^{\prime}$ and reverse, $5^{\prime}$-GAGGCCAATTTTGTCTCCACA-3'

\subsection{Caspase-8 and Caspase-1 Activity}

Total protein was obtained from corneal tissue or cell lysates by the Whole Cell Lysis Assay (KeyGen Biotech., Nanjing, China). Caspase-8 (Cat. No. K113) or caspase-1 (Cat. No. K111) activity of the corneas or cells was detected by the Colorimetric Assay Kit (BioVision, Milpitas, CA, USA) according to the manufacturer's protocol. Briefly, $200 \mu \mathrm{g}$ protein diluted to $50 \mu \mathrm{L}$ cell lysis buffer was mixed with $50 \mu \mathrm{L} 2 \mathrm{X}$ reaction buffer. Mixtures were incubated with IETD-p-nitroanilide (pNA) substrate (caspase-8) or YVAD-pNA substrate (caspase-1) in 96-plate well. After two hours of incubation at $37^{\circ} \mathrm{C}$, the pNA light emission is quantified using a spectrophotometer at $405 \mathrm{~nm}$ [25].

\subsection{Statistical Analysis}

One-way ANOVA with Tukey-Kramer post-hoc test was used to compare differences among three or more groups. Data analyses were performed using SPSS (22.0, IBM, Armonk, NY, USA). A value of $p<0.05$ was accepted as statistically significant.

\section{Results}

\subsection{Corneal $A B$ Induced $C N V$ and Increased Caspase-8 Activity}

In the $\mathrm{AB}$ model, exposure to $\mathrm{NaOH}(1 \mathrm{M})$ on the cornea resulted in time dependently increase in $\mathrm{CNV}$. We found that limbal vessels sprouted, gradually grew into the cornea and reached the center on day 14 after corneal AB $(p<0.01$, Figure $1 \mathrm{~A}, \mathrm{~B})$. The data also revealed that caspase- 8 activity in the injured corneas was notably elevated and remained increased after corneal $\mathrm{AB}(p<0.01$, Figure $1 \mathrm{C})$.

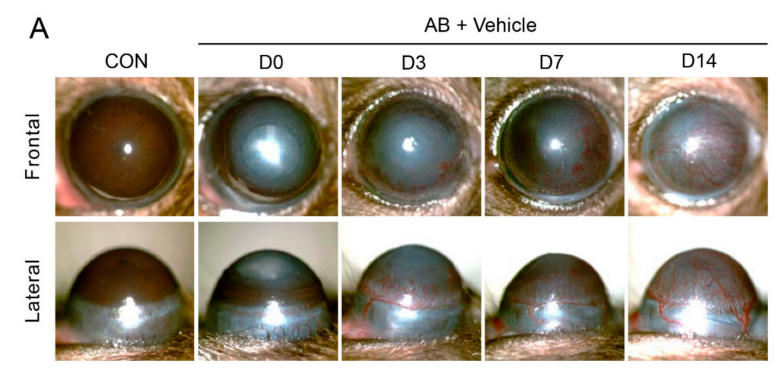

B

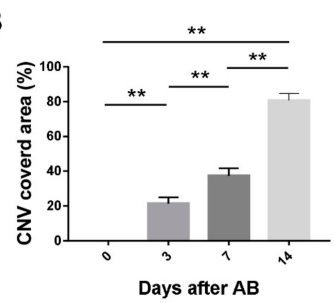

C

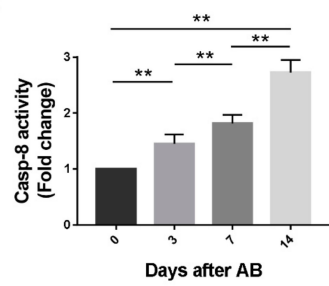

Figure 1. Corneal alkali burn (AB)-induced corneal neovascularization (CNV) and increased caspase-8 activity. (A) Representative photos of mouse eyes at $0,3,7$, and 14 days after corneal AB injury. (B) Statistical analysis of the CNV covered area at various time-points $(n=6)$. (C) Colorimetric assay of caspase- 8 activity in corneas $(n=3)$. The data are presented as the mean $\pm \mathrm{SD}$. ${ }^{* *} p<0.01$. Abbreviations: CON, control; Casp, caspase. 


\subsection{Pharmacological Inhibition of Caspase-8 Suppressed $C N V$ after Corneal $A B$}

Then, we detected the potential role of a caspase-8 inhibitor in the development of CNV. When Z-IETD-fmk, a specific caspase-8 inhibitor, was topically applied for 14 days after alkali-induced injury, macroscopic CNV was noticeably reduced. We used dose curve to select the most effective dose of inhibitor and a maximum inhibitory effect on CNV was observed with the $40 \mu \mathrm{M}$ dose $(p<0.01$, Figure 2A,B). A dose of $40 \mu \mathrm{M}$ was therefore used for subsequent experiments. Local administration of Z-IETD-fmk also resulted in the suppression of caspase-8 activity ( $20 \mu \mathrm{M}$ vs. $40 \mu \mathrm{M}, 40 \mu \mathrm{M}$ vs. $100 \mu \mathrm{M}$, $p<0.05$; vehicle vs. $40 \mu \mathrm{M}, p<0.01$, Figure 2C).

A

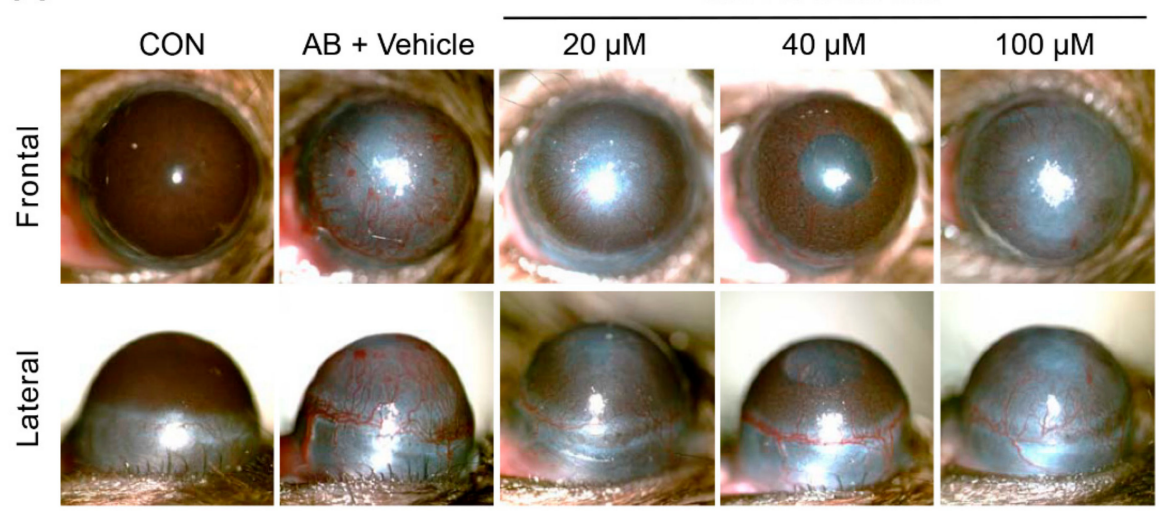

B

C
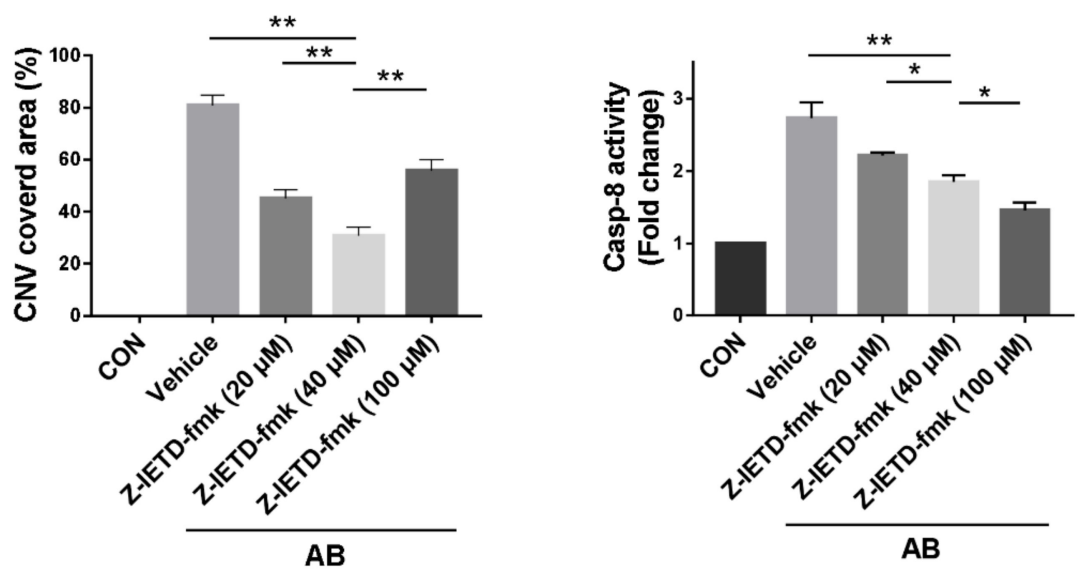

Figure 2. Pharmacological inhibition of caspase-8 suppressed CNV after corneal AB. (A) Representative images of the macroscopic CNV appearance after vehicle/Z-IETD-fmk treatment on day 14 after corneal AB injury. (B) Statistical analysis of the CNV covered area after vehicle/Z-IETD-fmk treatment $(n=6)$. (C) Colorimetric assay of caspase- 8 activity in corneas $(n=3)$. The data are presented as the mean \pm SD. ${ }^{*} p<0.05,{ }^{* *} p<0.01$.

\subsection{Pharmacological Inhibition of Caspase-8 Suppressed CD31 and VEGF-A Expression after Corneal AB}

Immunofluorescence analysis with an anti-CD31 antibody demonstrated a dramatic vascular area reduction in the experimental group compared with the vehicle group $(p<0.01$, Figure $3 \mathrm{~A}, \mathrm{~B})$. Consistently, the mRNA expression of the proangiogenic factor VEGF-A was notably upregulated after corneal $\mathrm{AB}$, whereas caspase-8 inhibition significantly reduced VEGF-A mRNA expression in injured corneas $(p<0.01$, Figure $3 C$ ). These findings collectively suggest that caspase-8 plays a pivotal role in $\mathrm{CNV}$ and that caspase- 8 inhibition is responsible for $\mathrm{CNV}$ suppression. 


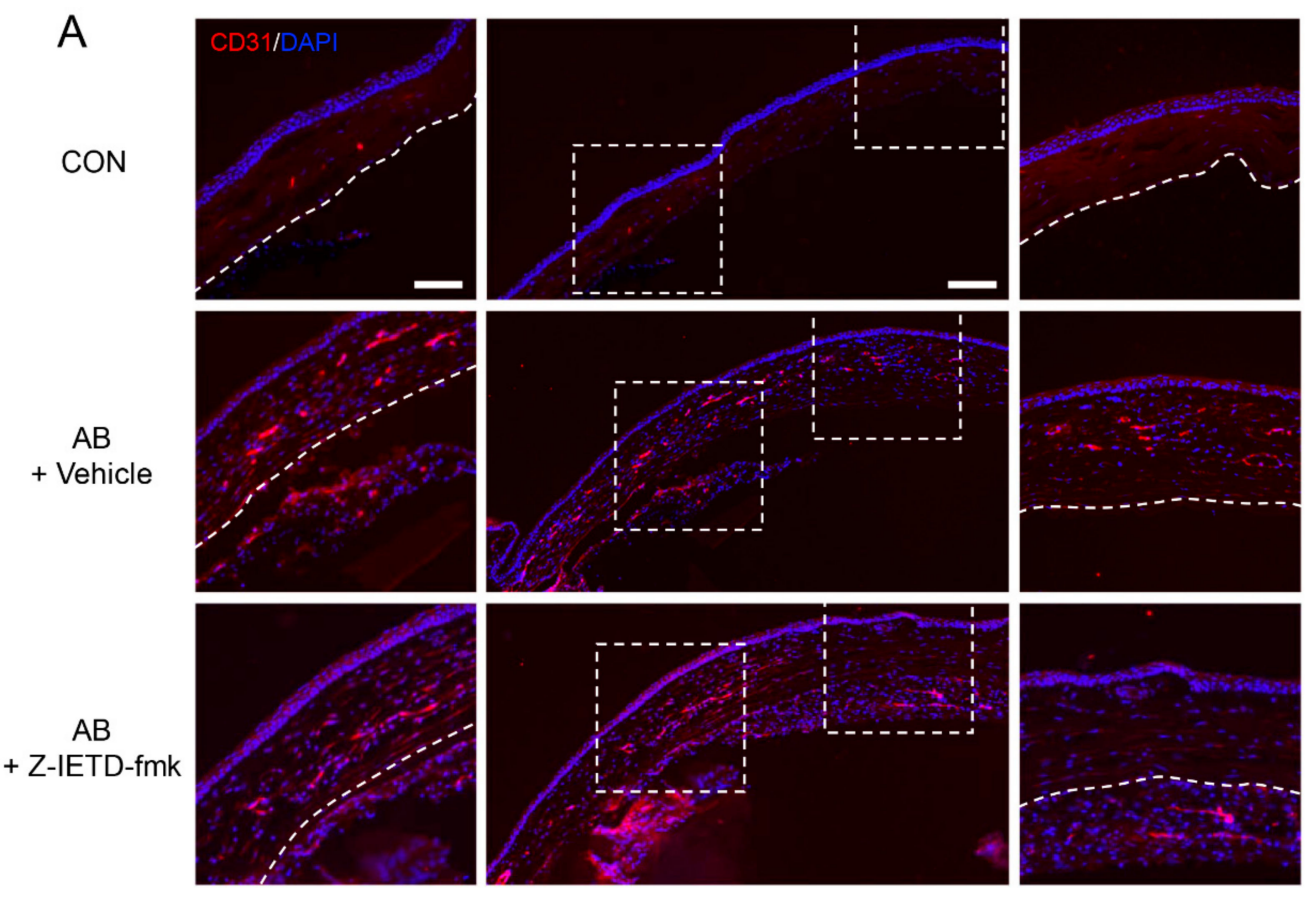

B
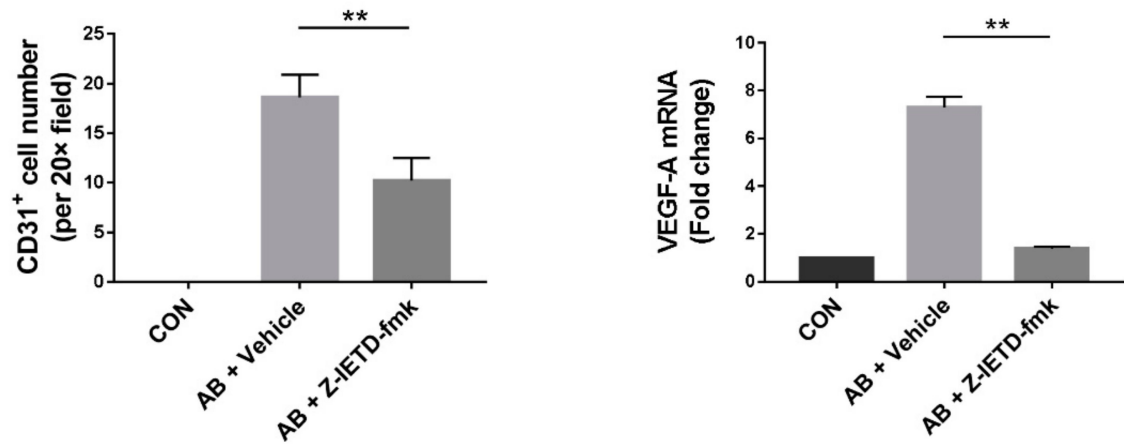

Figure 3. Pharmacological inhibition of caspase- 8 suppressed CD31 and VEGF-A expression after corneal AB. (A) Immunostaining of frozen corneal sections for CD31. White boxed areas in the middle micrographs (10× field) are magnified in the left and right panels (20× field). Scale bars: $200 \mu \mathrm{m}$ (middle), $100 \mu \mathrm{m}$ (left and right). White dotted line: outline of the corneal epithelium. (B) Statistical analysis of the CD31-positive cell numbers $(n=5)$. (C) RT-qPCR analysis of VEGF-A mRNA expression in corneas $(n=3)$. The data are presented as the mean \pm SD. ${ }^{* *} p<0.01$.

\subsection{Pharmacological Inhibition of Caspase-8 Suppressed Alkali-Induced Inflammation}

To investigate the underlying mechanism of caspase- 8 inhibition, we further analyzed the cornea sections. H\&E staining clearly showed that inflammatory cell infiltration was markedly increased in the alkali-injured corneas. Topical application of Z-IETD-fmk reduced the number of inflammatory cells $(p<0.01$, Figure 4A,B). The histological analysis of the corneal tissue supported the conclusion that the caspase-8 inhibitor suppressed inflammatory CNV. Correlatively, the RT-qPCR results revealed that the TNF- $\alpha$ and IL- $1 \beta$ mRNA levels were upregulated. However, the caspase- 8 inhibitor reversed the upregulation of the mRNA expression of these inflammatory cytokines $(p<0.01$, Figure 4 C,D). We also found that NLRP3 and ASC mRNA expression and caspase-1 activity were increased. Local administration of the caspase- 8 inhibitor markedly reduced these elevations $(p<0.01$, Figure 4E-G). 
A

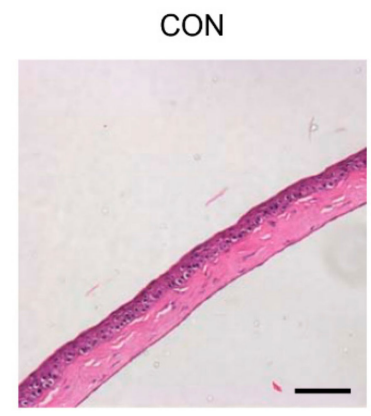

$\mathrm{AB}+$ Vehicle

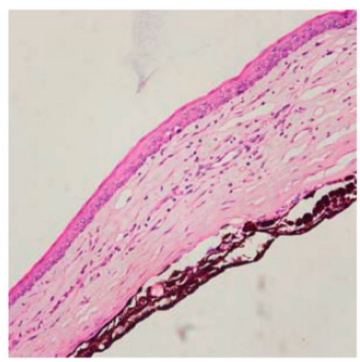

AB + Z-IETD-fmk

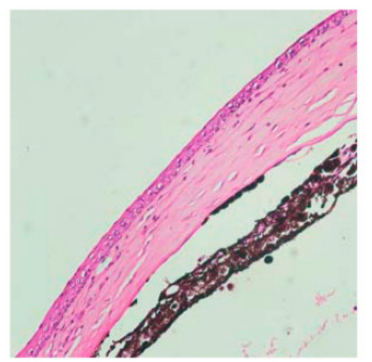

$\mathrm{D}$

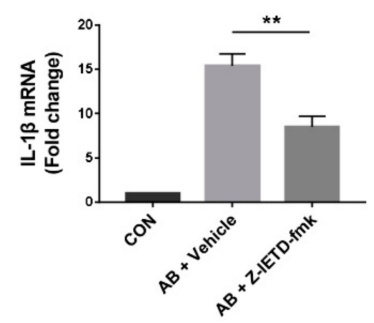

$G$
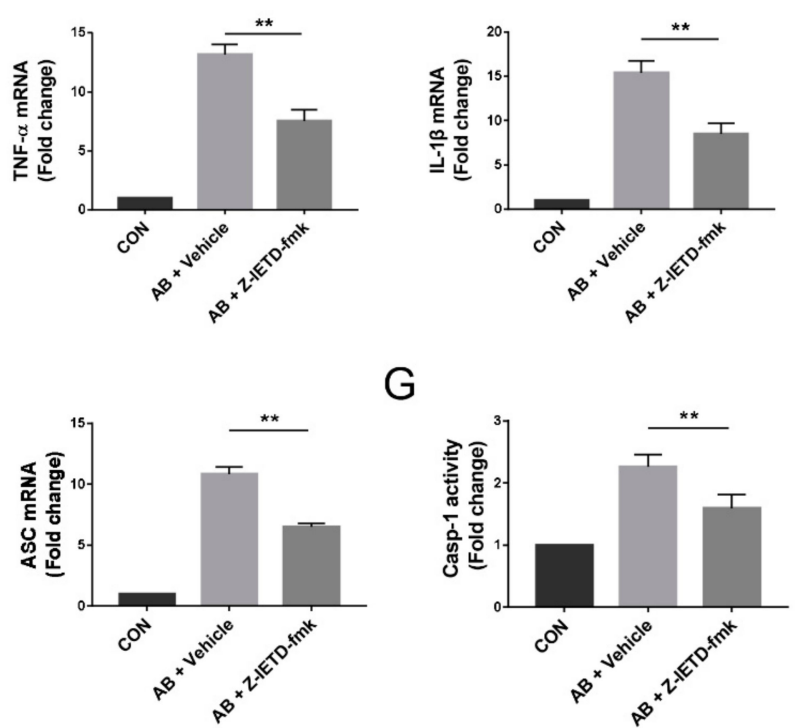

Figure 4. Pharmacological inhibition of caspase-8 suppressed alkali-induced inflammation and NLRP3 inflammasome activation. (A) Representative H\&E staining of the eye tissue from different groups $(20 \times$ field). Scale bars: $100 \mu \mathrm{m}$. (B) Histological analysis of inflammatory cell infiltration per $20 \times$ field $(\mathrm{n}=5)$. (C-F) RT-qPCR analysis of TNF- $\alpha$, IL-1 $\beta$, NLRP3, and ASC mRNA expression in corneas $(n=3)$. $(\mathbf{G})$ Colorimetric assay of caspase-1 activity in corneas $(n=3)$. The data are presented as the mean \pm SD. ${ }^{* *} p<0.01$.

\subsection{Pharmacological Inhibition of Caspase-8 Suppressed Macrophage Recruitment}

Macrophages are critically involved in CNV development [38-41]. Therefore, we subsequently investigated the role of caspase-8 in macrophage recruitment during $\mathrm{CNV}$ and examined the effects of caspase- 8 inhibition on macrophage accumulation in alkali-injured corneas. $\mathrm{F} 4 / 80^{+}$macrophage numbers were notably increased in the injured corneas on day 7 after corneal $\mathrm{AB}$ and were significantly decreased with caspase- 8 inhibition $(p<0.01$, Figure $5 \mathrm{~A}, \mathrm{~B})$. The expressions of macrophage-related chemokines MIP-1 and MCP-1 were upregulated in the alkali-injured corneas and were noticeably reduced in the caspase- 8 inhibitor-treated corneas $(p<0.01$, Figure $5 C, D)$, which indicated that caspase- 8 inhibitor could suppress macrophage recruitment. The above observations suggest that caspase- 8 signaling is important for $\mathrm{F} 4 / 80^{+}$macrophage recruitment and that this effect might be attributed to the caspase-8-mediated production of chemokines. 
A

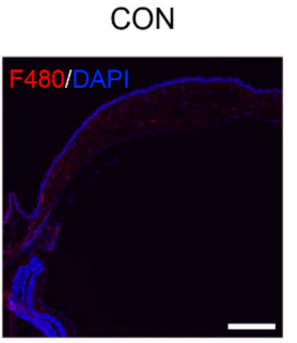

$\mathrm{AB}+$ Vehicle

$A B+$ Z-IETD-fmk
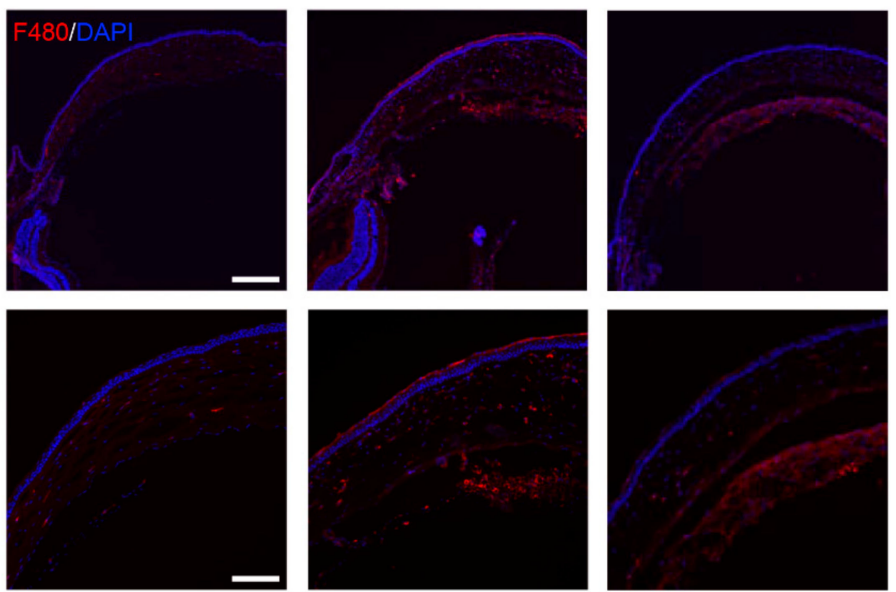

B
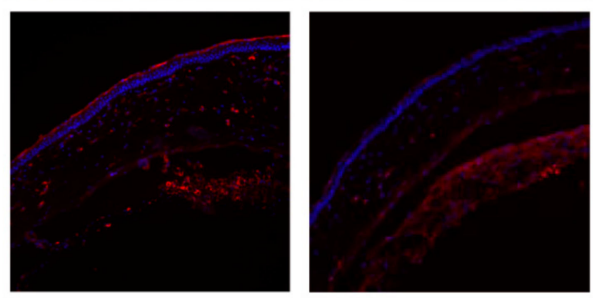

C

$\mathrm{D}$
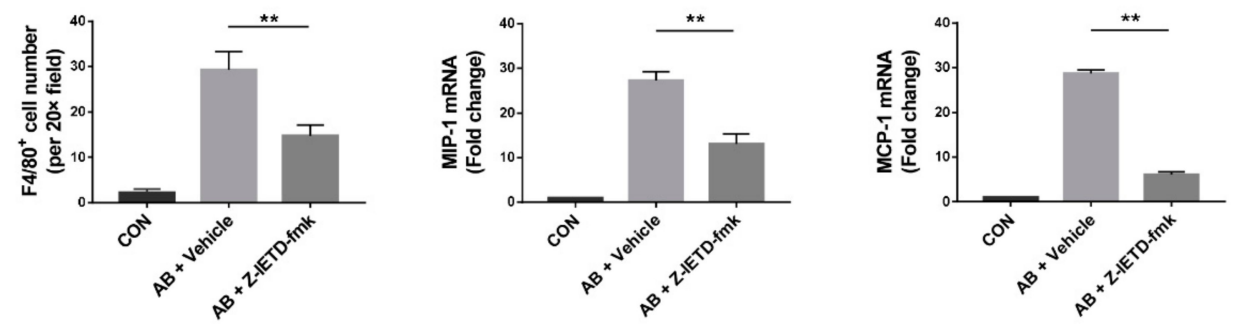

Figure 5. Pharmacological inhibition of caspase-8 suppressed macrophage recruitment. (A) Representative immunofluorescence micrographs of F4/80 staining. Scale bars: $200 \mu \mathrm{m}$ (upper, $10 \times$ field), $100 \mu \mathrm{m}$ (lower, $20 \times$ field). (B) Statistical analysis of F4/80-positive cell number $(n=5)$. (C,D) RT-qPCR analysis of MIP-1 and MCP-1 mRNA expression in corneas $(n=3)$. The data are presented as the mean $\pm \mathrm{SD}$. ${ }^{* *} p<0.01$.

3.6. Pharmacological Inhibition of Caspase-8 Suppressed the Inflammatory Profiles of Macrophage In Vitro

We performed in vitro studies in the RAW264.7 murine macrophage cell line to further elucidate the roles of caspase-8, macrophages, and the NLRP3 inflammasome in CNV. Our results showed that LPS $(100 \mathrm{ng} / \mathrm{mL})$ significantly elevated caspase-8 activity and upregulated VEGF-A, TNF- $\alpha$, IL-1 $\beta$, MIP-1, MCP-1, NLRP3, and ASC mRNA expression as well as caspase-1 activity in macrophages. The caspase-8 inhibitor Z-IETD-fmk $(10 \mu \mathrm{M})$, which did not affect cell viability $(p>0.05$, Figure $6 \mathrm{~J})$, blocked the impact of LPS ( $p<0.01$, Figure $6 \mathrm{~A}-\mathrm{I})$. Taken together, caspase-8 inhibition is able to block macrophage activation, contributing to the suppression of $\mathrm{CNV}$. 
A

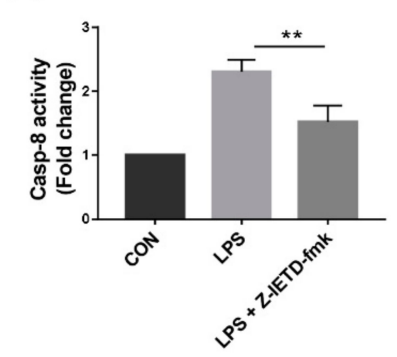

D

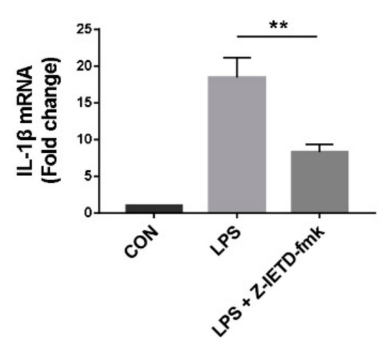

G
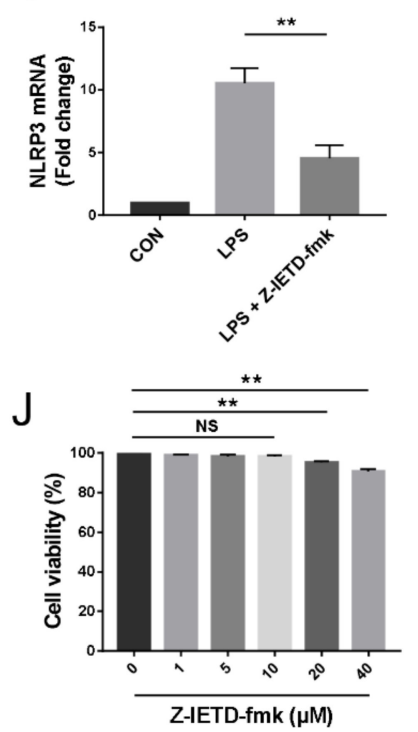

B

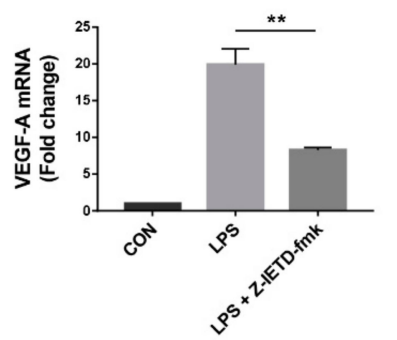

E

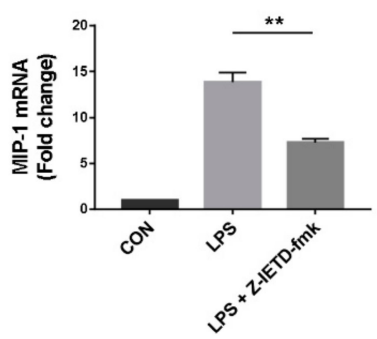

$\mathrm{H}$

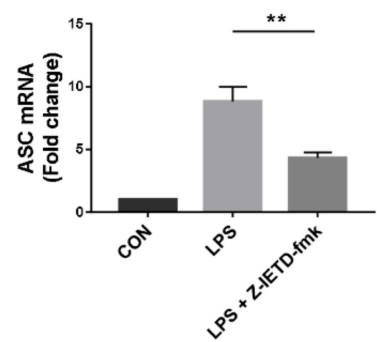

C

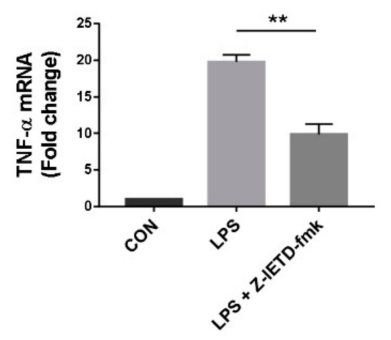

F

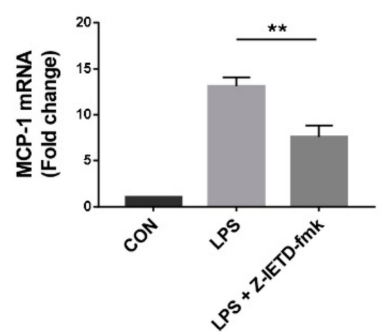

I

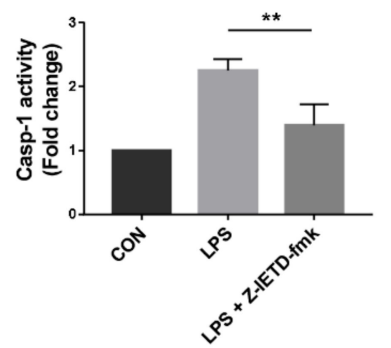

Figure 6. Pharmacological inhibition of caspase-8 suppressed the inflammatory profiles of RAW264.7 cells. (A) Colorimetric assay of caspase-8 activity in RAW264.7 cells $(n=3)$. (B-H) RT-qPCR analysis of VEGF-A, TNF- $\alpha$, IL-1 $\beta$, MIP-1, MCP-1, NLRP3, and ASC mRNA expression in RAW264.7 cells $(n=3)$. (I) Colorimetric assay of caspase-1 activity in RAW264.7 cells $(n=3)$. (J) Trypan blue exclusion assay for cell viability $(n=3)$. The data are presented as the mean \pm SD. NS $p>0.05,{ }^{* *} p<0.01$.

\subsection{Caspase-8 Activity was Partially Regulated by TLR4 Signaling}

Our in vitro experiments showed that a TLR4 agonist stimulated caspase-8 activity, and caspase-8 inhibition blocked TLR4-depentent macrophage activation. We, thus, investigated whether TLR4 signaling regulates caspase- 8 activity in CNV after AB. TLR4 mRNA expression was significantly increased in the alkali-burned corneas of WT mice and remained elevated 14 days after $\mathrm{AB}(p<0.01$, Figure 7A). Using Tlr ${ }^{-/}$mice, our results show that caspase-8 activity and CNV in the injured corneas was increased after AB. TLR4 knockout noticeably but only partially reduced caspase- 8 activity after $\mathrm{AB}\left(p<0.01\right.$, Figure 7B). Furthermore, CNV was significantly reduced in $T l r 4^{-/}$mice in comparison with WT mice $(p<0.01$, Figure 7C,D). Consistently, the RT-qPCR results revealed that the VEGF-A, 
inflammatory cytokines, and chemokines mRNA levels were elevated after AB in $T l r 4^{-/}$mice but were downregulated comparing with the WT mice $(p<0.01$, Figure 7E-I). Therefore, TLR4 signaling plays an important role in the activation of caspase- 8 in $\mathrm{CNV}$ after $\mathrm{AB}$.
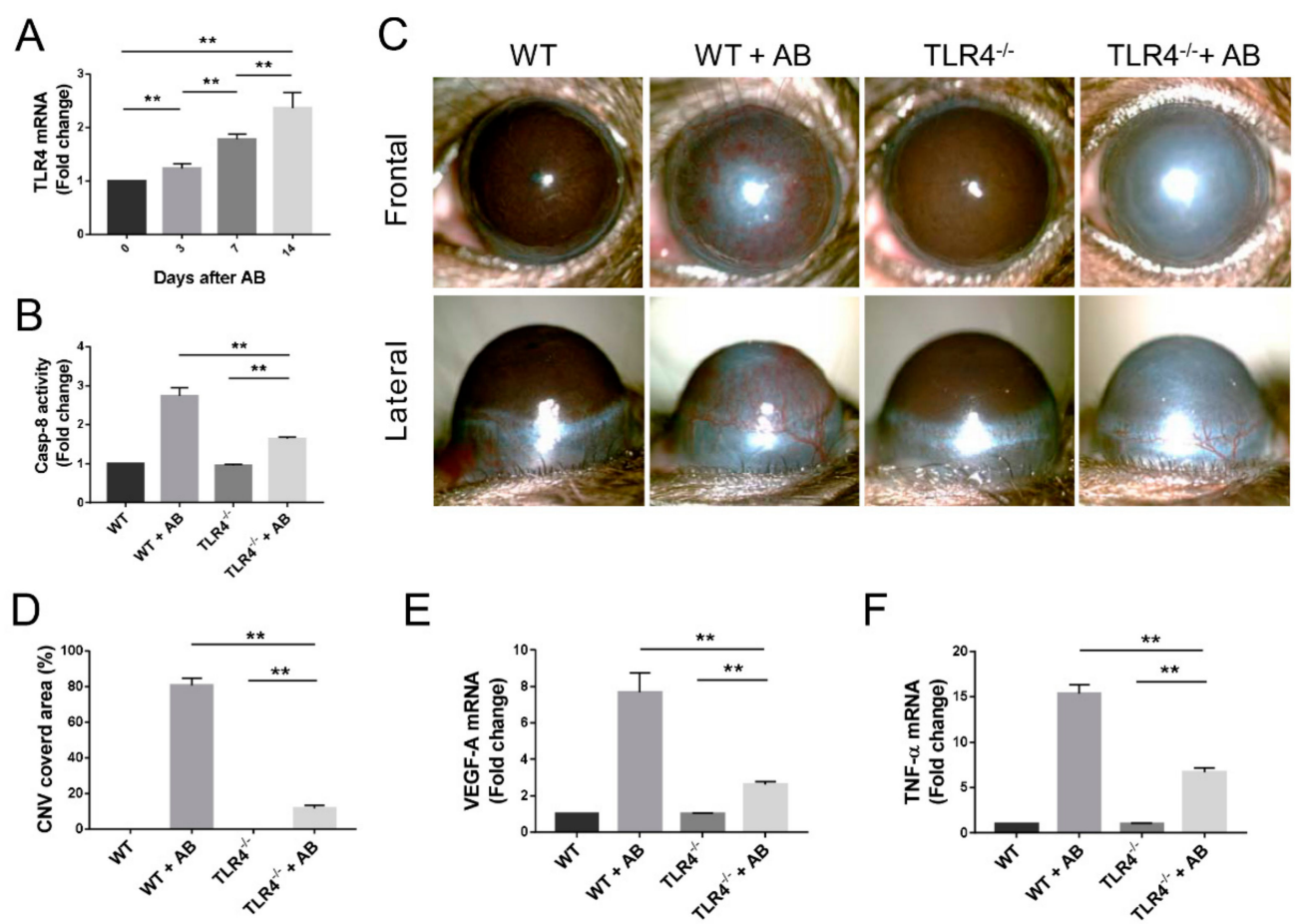

$E$
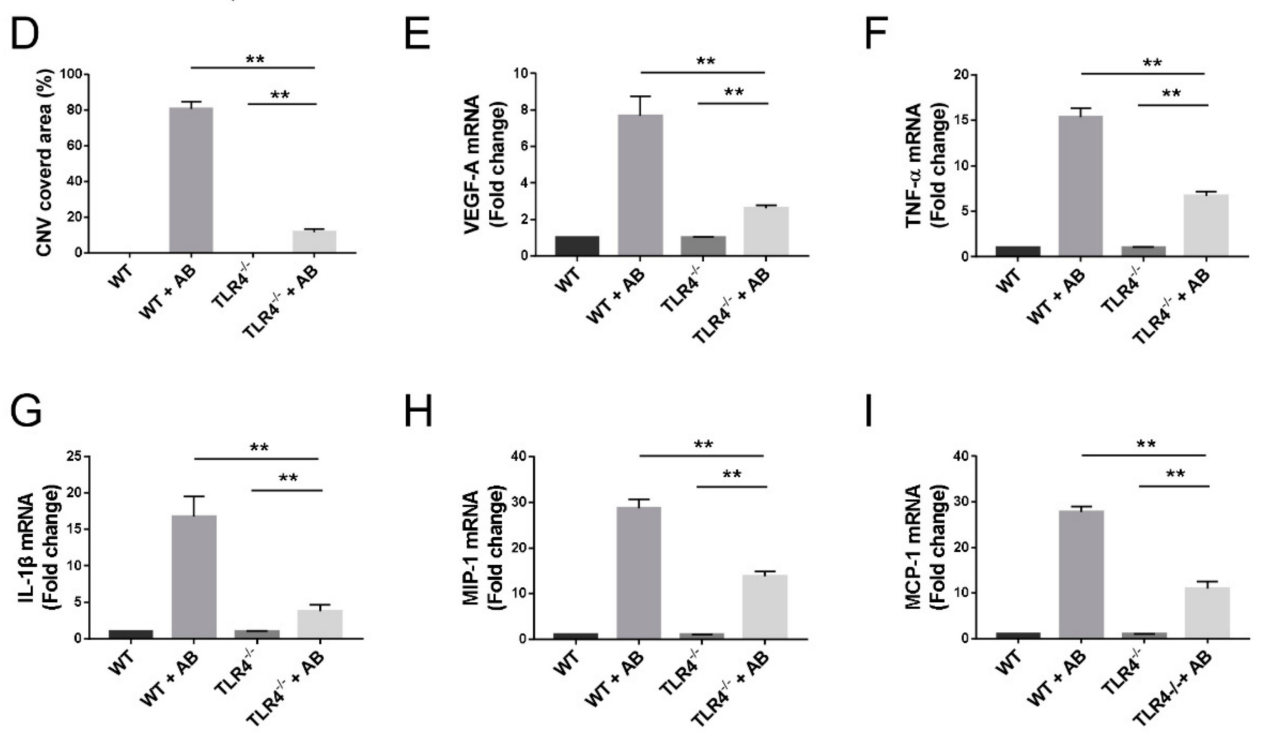

$\mathrm{H}$
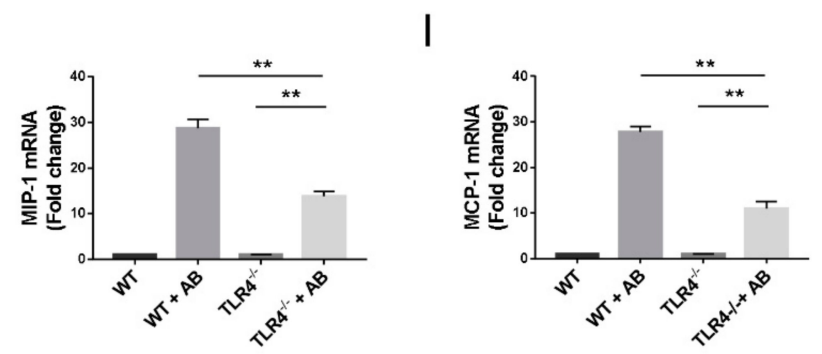

Figure 7. Caspase-8 activity is partially regulated by TLR4 signaling. (A) RT-qPCR analysis of TLR4 mRNA expression in corneas of WT mice at various time-points $(n=3)$. (B) Colorimetric assay of caspase-8 activity in corneas $(n=3)$. (C) Representative images of the macroscopic CNV appearance on WT and TLR4 ${ }^{-/}$mice on day 14 after corneal AB injury. (D) Statistical analysis of the CNV covered area of WT and TLR4 ${ }^{-/}$mice $(n=6)$. (E-I) RT-qPCR analysis of VEGF-A, TNF- $\alpha$, IL-1 $\beta$, MIP-1, and MCP-1 mRNA expression in corneas $(n=3)$. The data are presented as the mean \pm SD. ${ }^{* *} p<0.01$.

\section{Discussion}

This study shows that pharmacological caspase- 8 inhibition is a feasible and effective treatment strategy for $\mathrm{CNV}$ and identifies the key role of caspase- 8 in $\mathrm{CNV}$ after corneal $\mathrm{AB}$. We found that corneal $\mathrm{AB}$ induced $\mathrm{CNV}$ and increased caspase- 8 activity and that caspase-8 inhibition had substantial suppressive effects on $\mathrm{CNV}$, with consistent decreases in caspase-8 activity, inflammatory cell infiltration, $\mathrm{F} 4 / 80^{+}$macrophage recruitment and activation, VEGF-A, inflammatory cytokines and chemokines expression in the cornea after corneal AB. In vitro, a caspase-8 inhibitor reversed the LPS-induced increases in VEGF-A, TNF- $\alpha$, IL-1 $\beta$, MIP-1, and MCP-1 mRNA expression in macrophages. Taken together, our current findings demonstrate the therapeutic effects of the pharmacological caspase- 8 inhibition on $\mathrm{CNV}$ and elucidate a novel mechanism whereby caspase-8 promotes $\mathrm{CNV}$ in corneal $\mathrm{AB}$. 
Caspase-8, which is well acknowledged as the initiator of apoptotic signaling, has also been shown to possess numerous immune properties [18-21]. Burguillos et al. found that caspase-8 mediates TLR4-dependent microglial activation and neuroinflammation [18]. Kim et al. and Qi et al. reported that caspase-8 promotes inflammation in cancer and asthma, respectively [20,21]. Recently, our group showed that caspase- 8 promotes inflammatory lymphangiogenesis and allograft rejection in corneal transplantation [25]. Moreover, it has been demonstrated that the caspase-8 promotes NF- $\kappa B$ pathway activation to control microglia activation and IL- $1 \beta$, TNF- $\alpha$ production to promote neuroinflammation [18]. A study found that caspase-8 activates NLRP3 inflammasome and increases IL-1 $\beta$ production in acute glaucoma [24]. Therefore, caspase- 8 may upregulate inflammatory cytokines expression to promote inflammation via the NF-KB pathway or/and NLRP3 inflammasome. In the present study, we made new observations, namely, that caspase- 8 activity is increased in the cornea after corneal $\mathrm{AB}$ and that caspase- 8 inhibition suppresses $\mathrm{CNV}$. In line with previous studies, we found that caspase- 8 activity is increased concurrently with increased NLRP3 inflammasome activity and relevant cytokines/chemokines expression, whereas the blockade of caspase-8 prevents NLRP3 inflammasome activation and decreases those cytokines/chemokines expression in the cornea after corneal AB. LPS also significantly elevates caspase-8 activity, NLRP3 inflammasome activity, and relevant cytokines/chemokines expression in vitro. These findings suggest that caspase- 8 is a crucial mediator of $\mathrm{CNV}$ in corneal $\mathrm{AB}$, and caspase-8 may affect those cytokines/chemokines expression through the NF-KB pathway or/and NLRP3 inflammasome.

Macrophages play critical roles in angiogenesis [38-41]. During angiogenesis, macrophages differentiate into an angiogenic phenotype. Activated macrophages secrete proangiogenic factors, inflammatory cytokines, and chemokines, which provoke the division and proliferation of preexisting vascular endothelial cells and recruit more macrophages to the inflamed tissue or tumor [38-41]. The present study showed that by blocking caspase- 8 with an inhibitor, it might be possible to reduce the recruitment of macrophages and decrease the expression of MIP-1 and MCP-1, which have been shown to play critical roles in the recruitment of these cells [42]. Notably, the subsequent decrease in macrophage recruitment is consistent with the inhibitory effects on VEGF-A, TNF- $\alpha$, and IL-1 $\beta$ expression. Furthermore, in vitro, caspase- 8 inhibition also leads to decreased VEGF-A, TNF- $\alpha$, IL-1 $\beta$, MIP-1, and MCP-1 expression in RAW264.7 cells stimulated with LPS. These results suggest that corneal $\mathrm{AB}$ may first induce resident corneal cell injury and/or activation to release MCP-1 and MIP-1, which then recruit and activate macrophages. Eventually, activated macrophages may produce VEGF-A, TNF- $\alpha$, IL-1 $\beta$, MIP-1, MCP-1, and other mediators to further promote CNV.

Toll-like receptor 4 (TLR4) is a key pattern recognition receptor (PRR) that recognizes molecular patterns associated with microbial pathogens and damage-associated molecular pattern (DAMP) molecules [43,44]. HMGB1, an endogenous ligand of TLR4, can drive the pathogenesis of inflammatory and angiogenic diseases and immune regulation, such as $\mathrm{CNV}$, ischemia-reperfusion injury and hemorrhagic shock, though HMGB1/TLR4 signaling pathway [45-48]. TLR4/caspase-8 signaling pathway also plays pivotal roles in various inflammation $[24,49,50]$. Chi et al. reported that TLR4/caspase- 8 pathway activation results in the maturation of IL- $1 \beta$ and aggravates the inflammation in acute glaucoma [24]. Shenderov et al. showed that, in the situation of endoplasmic reticulum stress, TLR4 activation stimulates IL-1 $\beta$ expression regulated by caspase-8 [49]. Philip et al. revealed that caspase- 8 mediates the induction of inflammatory cytokines caused by a bacterial infection and TLR activation [50]. Recently, it has been reported that HMGB1/TLR4 mediates caspase-8 activation to promote allograft rejection in corneal transplantation [25]. In our study, we found that the absence of TLR4 is associated with downregulated caspase- 8 activation, indicating that TLR4 is one of the upstream signals of caspase- 8 . Taken together, it is possible that the corneal AB initially leads to corneal cell damage. DAMP molecules released from damaged cells, such as HMGB1, combines with TLR4 to activate caspase-8 signaling promoting $\mathrm{CNV}$ in the cornea. However, we found that knockdown of TLR4 can reduce caspase- 8 activity, but not abrogate the increase of caspase- 8 . It has been reported that besides TLR4, HMGB1 can activate other TLRs like TLR2 and receptors for advanced glycation 
end products (RAGE), leading to the production and secretion of pro-inflammatory cytokines [51,52]. On the other hand, Chi et al. demonstrated that HMGB1/capase-8 pathway promotes the activation of NF- $k B$, which subsequently induces the processing of IL-1 $\beta$ and aggravates the inflammation [53]. Therefore, it is possible that caspase- 8 is also regulated by other signals, such as TLR2, during the inflammation in AB model, and TLR4 is only partially responsible for caspase- 8 activity.

Recently, Ueta et al. demonstrated that in pathological angiogenesis mouse model, RIPK1 abundantly expresses in infiltrating macrophages and inhibition of RIPK1 alleviates angiogenesis. Furthermore, caspase inhibition can augment RIPK1 activation, which cause aggravation of pathological angiogenesis [54]. Similarly, during the study, we found that $100 \mu \mathrm{M}$ Z-IETD-fmk treatment decreases the activity of caspase- 8 but aggravates CNV comparing with the $40 \mu \mathrm{M}$ group. Therefore, it is possible that high concentration of Z-IETD-fmk suppresses caspase-8 activity, resulting in inhibition of RIP kinase activation and aggravation of pathological angiogenesis. In this study, we focus on the function of caspase- 8 during inflammation-induced angiogenesis. However, the mechanism of caspase-8-mediated inflammation is largely unclear and needed to be explored in further study.

In conclusion, this study, to the best of our knowledge, presents a new mechanism by which caspase- 8 promotes inflammation-induced angiogenesis and reveals for the first time that the pharmacological inhibition of caspase- 8 suppresses inflammation-induced angiogenesis. They support the use of a pharmacological caspase-8 inhibitor as a novel clinical treatment for CNV and other angiogenic disorders.

Author Contributions: Y.T., H.L. and X.L. were responsible for the conception and design, data collection and assembly, manuscript writing, and final manuscript approval. X.L., L.X., Z.H., W.L., Z.L., Y.P., and X.C. were responsible for data collection and assembly. W.S. was responsible for conception and design, manuscript writing, and final manuscript approval. All authors have read and agreed to the published version of the manuscript.

Funding: This study was supported by the National Key R\&D Program of China (2017YFA0105800), the Natural Science Foundation of China (81670897), Guangdong Natural Science Funds for Distinguished Young Scholar (2016A030306006).

Conflicts of Interest: The authors declare that they have no conflict of interest.

\section{Abbreviations}

$\begin{array}{ll}\text { AB } & \text { alkali burn } \\ \text { CNV } & \text { corneal neovascularization } \\ \text { NLRP3 } & \text { Nod-like receptor family pyrin domain-containing 3 } \\ \text { ASC } & \text { apoptosis-associated speck-like protein containing CARD } \\ \text { WT } & \text { wild-type } \\ \text { TLR4 } & \text { toll like receptor } 4 \\ \text { SPF } & \text { specific pathogen-free } \\ \text { PFA } & \text { paraformaldehyde } \\ \text { BSA } & \text { bovine serum albumin } \\ \text { TBS } & \text { Tris-buffered saline } \\ \text { DMEM } & \text { Dulbecco's modified Eagle's medium } \\ \text { FBS } & \text { fetal bovine serum } \\ \text { LPS } & \text { lipopolysaccharide } \\ \text { VEGF-A } & \text { vascular endothelial growth factor-A } \\ \text { TNF- } \alpha & \text { tumor necrosis factor alpha } \\ \text { IL-1 } \beta & \text { interleukin-1 beta } \\ \text { MIP-1 } & \text { macrophage inflammatory protein-1 } \\ \text { MCP-1 } & \text { monocyte chemoattractant protein-1 } \\ \text { CON } & \text { control } \\ \text { Casp } & \text { caspase }\end{array}$




\section{References}

1. Szade, A.; Grochot-Przeczek, A.; Florczyk, U.; Jozkowicz, A.; Dulak, J. Cellular and molecular mechanisms of inflammation-induced angiogenesis. IUBMB Life 2015, 67, 145-159. [CrossRef] [PubMed]

2. Hanahan, D.; Folkman, J. Patterns and emerging mechanisms of the angiogenic switch during tumorigenesis. Cell 1996, 86, 353-364. [CrossRef]

3. Khurana, R.; Simons, M.; Martin, J.F.; Zachary, I.C. Role of angiogenesis in cardiovascular disease: a critical appraisal. Circulation 2005, 112, 1813-1824. [CrossRef] [PubMed]

4. Elshabrawy, H.A.; Chen, Z.; Volin, M.V.; Ravella, S.; Virupannavar, S.; Shahrara, S. The pathogenic role of angiogenesis in rheumatoid arthritis. Angiogenesis 2015, 18, 433-448. [CrossRef]

5. Witmer, A.N.; Vrensen, G.F.; Van Noorden, C.J.; Schlingemann, R.O. Vascular endothelial growth factors and angiogenesis in eye disease. Prog. Retin Eye Res. 2003, 22, 1-29. [CrossRef]

6. Gariano, R.F.; Gardner, T.W. Retinal angiogenesis in development and disease. Nature 2005, 438, 960-966. [CrossRef]

7. $\quad$ Ellenberg, D.; Azar, D.T.; Hallak, J.A.; Tobaigy, F.; Han, K.Y.; Jain, S.; Zhou, Z.; Chang, J.H. Novel aspects of corneal angiogenic and lymphangiogenic privilege. Prog. Retin Eye Res. 2010, 29, 208-248. [CrossRef]

8. Wang, Z.; Dabrosin, C.; Yin, X.; Fuster, M.M.; Arreola, A.; Rathmell, W.K.; Generali, D.; Nagaraju, G.P.; El-Rayes, B.; Ribatti, D.; et al. Broad targeting of angiogenesis for cancer prevention and therapy. Semin. Cancer Biol. 2015, 35, S224-S243. [CrossRef]

9. Doyle, B.; Caplice, N. Plaque neovascularization and antiangiogenic therapy for atherosclerosis. J. Am. Coll. Cardiol. 2007, 49, 2073-2080. [CrossRef]

10. Jiang, S.; Li, Y.; Lin, T.; Yuan, L.; Li, Y.; Wu, S.; Xia, L.; Shen, H.; Lu, J. IL-35 Inhibits Angiogenesis through VEGF/Ang2/Tie2 Pathway in Rheumatoid Arthritis. Cell Physiol. Biochem. 2016, 40, 1105-1116. [CrossRef]

11. Lim, L.S.; Mitchell, P.; Seddon, J.M.; Holz, F.G.; Wong, T.Y. Age-related macular degeneration. Lancet 2012, 379, 1728-1738. [CrossRef]

12. Wong, T.Y.; Cheung, C.M.; Larsen, M.; Sharma, S.; Simó, R. Diabetic retinopathy. Nat. Rev. Dis. Primers 2016, 2, 16012. [CrossRef] [PubMed]

13. Chang, J.H.; Garg, N.K.; Lunde, E.; Han, K.Y.; Jain, S.; Azar, D.T. Corneal neovascularization: an anti-VEGF therapy review. Surv. Ophthalmol. 2012, 57, 415-429. [CrossRef] [PubMed]

14. Man, S.M.; Kanneganti, T.D. Converging roles of caspases in inflammasome activation, cell death and innate immunity. Nat. Rev. Immunol. 2016, 16, 7-21. [CrossRef]

15. Feltham, R.; Vince, J.E.; Lawlor, K.E. Caspase-8: not so silently deadly. Clin. Transl. Immunol. 2017, 6, e124. [CrossRef]

16. Crowder, R.N.; El-Deiry, W.S. Caspase-8 regulation of TRAIL-mediated cell death. Exp. Oncol. 2012, 34, 160-164.

17. Tezel, G.; Wax, M.B. Inhibition of caspase activity in retinal cell apoptosis induced by various stimuli in vitro. Invest. Ophthalmol. Vis. Sci. 1999, 40, 2660-2667.

18. Burguillos, M.A.; Deierborg, T.; Kavanagh, E.; Persson, A.; Hajji, N.; Garcia-Quintanilla, A.; Cano, J.; Brundin, P.; Englund, E.; Venero, J.L.; et al. Caspase signalling controls microglia activation and neurotoxicity. Nature 2011, 472, 319-324. [CrossRef]

19. Gao, Y.; Tang, J.; Chen, W.; Li, Q.; Nie, J.; Lin, F.; Wu, Q.; Chen, Z.; Gao, Z.; Fan, H.; et al. Inflammation negatively regulates FOXP3 and regulatory T-cell function via DBC1. Proc. Natl. Acad. Sci. USA 2015, 112, E3246-E3254. [CrossRef]

20. Kim, S.B.; Kim, H.R.; Park, M.C.; Cho, S.; Goughnour, P.C.; Han, D.; Yoon, I.; Kim, Y.; Kang, T.; Song, E. Caspase-8 controls the secretion of inflammatory lysyl-tRNA synthetase in exosomes from cancer cells. J. Cell Biol. 2017, 216, 2201-2216. [CrossRef]

21. Qi, X.; Gurung, P.; Malireddi, R.K.; Karmaus, P.W.; Sharma, D.; Vogel, P.; Chi, H.; Green, D.R.; Kanneganti, T.D. Critical role of caspase-8-mediated IL-1 signaling in promoting Th2 responses during asthma pathogenesis. Mucosal Immunol. 2017, 10, 128-138. [CrossRef] [PubMed]

22. Strowig, T.; Henao-Mejia, J.; Elinav, E.; Flavell, R. Inflammasomes in health and disease. Nature 2012, 481, 278-286. [CrossRef] [PubMed] 
23. Antonopoulos, C.; Russo, H.M.; El Sanadi, C.; Martin, B.N.; Li, X.; Kaiser, W.J.; Mocarski, E.S.; Dubyak, G.R. Caspase-8 as an Effector and Regulator of NLRP3 Inflammasome Signaling. J. Biol. Chem. 2015, 290, 20167-20184. [CrossRef] [PubMed]

24. Chi, W.; Li, F.; Chen, H.; Wang, Y.; Zhu, Y.; Yang, X.; Zhu, J.; Wu, F.; Ouyang, H.; Ge, J.; et al. Caspase-8 promotes NLRP1/NLRP3 inflammasome activation and IL-1 $\beta$ production in acute glaucoma. Proc. Natl. Acad. Sci. USA 2014, 111, 11181-11186. [CrossRef]

25. Su, W.; Han, L.; Chen, X.; Yu, J.; Cheng, X.; Huang, J.; Xiao, Y.; Tian, Y.; Olsen, N.; Zheng, S.G.; et al. Pharmacological inhibition of caspase-8 suppresses inflammation-induced lymphangiogenesis and allograft rejection in the cornea. J. Allergy Clin. Immunol. 2018, 142, 290-294.e9. [CrossRef]

26. Fianco, G.; Mongiardi, M.P.; Levi, A.; De Luca, T.; Desideri, M.; Trisciuoglio, D.; Del Bufalo, D.; Cinà, I.; Di Benedetto, A.; Mottolese, M.; et al. Caspase- 8 contributes to angiogenesis and chemotherapy resistance in glioblastoma. eLife 2017, 6. [CrossRef]

27. Gao, N.; Liu, X.; Wu, J.; Li, J.; Dong, C.; Wu, X.; Xiao, X.; Yu, F.X. CXCL10 suppression of hem- and lymph-angiogenesis in inflamed corneas through MMP13. Angiogenesis 2017, 20, 505-518. [CrossRef]

28. Lennikov, A.; Mirabelli, P.; Mukwaya, A.; Schaupper, M.; Thangavelu, M.; Lachota, M.; Ali, Z.; Jensen, L.; Lagali, N. Selective IKK2 inhibitor IMD0354 disrupts NF- $\mathrm{kB}$ signaling to suppress corneal inflammation and angiogenesis. Angiogenesis 2018, 21, 267-285. [CrossRef]

29. Baradaran-Rafii, A.; Eslani, M.; Haq, Z.; Shirzadeh, E.; Huvard, M.J.; Djalilian, A.R. Current and Upcoming Therapies for Ocular Surface Chemical Injuries. Ocul. Surf. 2017, 15, 48-64. [CrossRef]

30. Mulik, S.; Xu, J.; Reddy, P.B.; Rajasagi, N.K.; Gimenez, F.; Sharma, S.; Lu, P.Y.; Rouse, B.T. Role of miR-132 in angiogenesis after ocular infection with herpes simplex virus. Am. J. Pathol. 2012, 181, 525-534. [CrossRef]

31. Suryawanshi, A.; Veiga-Parga, T.; Reddy, P.B.; Rajasagi, N.K.; Rouse, B.T. IL-17A differentially regulates corneal vascular endothelial growth factor (VEGF)-A and soluble VEGF receptor 1 expression and promotes corneal angiogenesis after herpes simplex virus infection. J. Immunol. 2012, 188, 3434-3446. [CrossRef] [PubMed]

32. Poon, M.W.; Yan, L.; Jiang, D.; Qin, P.; Tse, H.F.; Wong, I.Y.; Wong, D.S.; Tergaonkar, V.; Lian, Q. Inhibition of RAP1 enhances corneal recovery following alkali injury. Invest. Ophthalmol. Vis. Sci. 2015, 56, 711-721. [CrossRef] [PubMed]

33. Seo, M.; Choi, J.S.; Rho, C.R.; Joo, C.K.; Lee, S.K. MicroRNA miR-466 inhibits Lymphangiogenesis by targeting prospero-related homeobox 1 in the alkali burn corneal injury model. J. Biomed. Sci. 2015, 22, 3. [CrossRef] [PubMed]

34. Anderson, C.; Zhou, Q.; Wang, S. An alkali-burn injury model of corneal neovascularization in the mouse. J. Vis. Exp. 2014, 86. [CrossRef]

35. Hua, X.; Yuan, X.; Li, Y.; Chen, H.; Yuan, J.; Tanumiharjo, S.; Bian, F.; Su, L.; Hong, Y.; Liu, Y.; et al. Desiccating stress worsens alkali burn injury by magnifying caspase-8-induced imbalance of NLRP3 and NLRP6. J. Allergy Clin. Immunol 2017, 140, 1172-1176.e3. [CrossRef]

36. Su, W.; Li, Z.; Li, Y.; Lin, M.; Yao, L.; Liu, Y.; He, Z.; Wu, C.; Liang, D. Doxycycline enhances the inhibitory effects of bevacizumab on corneal neovascularization and prevents its side effects. Invest. Ophthalmol. Vis. Sci. 2011, 52, 9108-9115. [CrossRef]

37. D'Amato, R.J.; Loughnan, M.S.; Flynn, E.; Folkman, J. Thalidomide is an inhibitor of angiogenesis. Proc. Natl. Acad. Sci. USA 1994, 91, 4082-4085. [CrossRef]

38. Sunderkötter, C.; Steinbrink, K.; Goebeler, M.; Bhardwaj, R.; Sorg, C. Macrophages and angiogenesis. J. Leukoc. Biol. 1994, 55, 410-422. [CrossRef]

39. Lamagna, C.; Aurrand-Lions, M.; Imhof, B.A. Dual role of macrophages in tumor growth and angiogenesis. J. Leukoc. Biol. 2006, 80, 705-713. [CrossRef]

40. David Dong, Z.M.; Aplin, A.C.; Nicosia, R.F. Regulation of angiogenesis by macrophages, dendritic cells, and circulating myelomonocytic cells. Curr. Pharm. Des. 2009, 15, 365-379. [CrossRef]

41. Riabov, V.; Gudima, A.; Wang, N.; Mickley, A.; Orekhov, A.; Kzhyshkowska, J. Role of tumor associated macrophages in tumor angiogenesis and lymphangiogenesis. Front. Physiol. 2014, 5, 75. [CrossRef]

42. Gillitzer, R.; Goebeler, M. Chemokines in cutaneous wound healing. J. Leukoc. Biol. 2001, 69, 513-521.

43. Kawai, T.; Akira, S. Toll-like receptors and their crosstalk with other innate receptors in infection and immunity. Immunity 2011, 34, 637-650. [CrossRef] [PubMed] 
44. Broz, P.; Monack, D.M. Newly described pattern recognition receptors team up against intracellular pathogens. Nat. Rev. Immunol. 2013, 13, 551-565. [CrossRef] [PubMed]

45. Tsung, A.; Tohme, S.; Billiar, T.R. High-mobility group box-1 in sterile inflammation. J. Intern. Med. 2014, 276, 425-443. [CrossRef] [PubMed]

46. Lin, Q.; Yang, X.P.; Fang, D.; Ren, X.; Zhou, H.; Fang, J.; Liu, X.; Zhou, S.; Wen, F.; Yao, X.; et al. High-mobility group box-1 mediates toll-like receptor 4-dependent angiogenesis. Arterioscler. Thromb. Vasc. Biol. 2011, 31, 1024-1032. [CrossRef]

47. Kim, J.Y.; Park, J.S.; Strassheim, D.; Douglas, I.; Diaz del Valle, F.; Asehnoune, K.; Mitra, S.; Kwak, S.H.; Yamada, S.; Maruyama, I.; et al. HMGB1 contributes to the development of acute lung injury after hemorrhage. Am. J. Physiol. Lung Cell Mol. Physiol. 2005, 288, L958-L965. [CrossRef]

48. Tsung, A.; Zheng, N.; Jeyabalan, G.; Izuishi, K.; Klune, J.R.; Geller, D.A.; Lotze, M.T.; Lu, L.; Billiar, T.R. Increasing numbers of hepatic dendritic cells promote HMGB1-mediated ischemia-reperfusion injury. J. Leukoc. Biol. 2007, 81, 119-128. [CrossRef]

49. Shenderov, K.; Riteau, N.; Yip, R.; Mayer-Barber, K.D.; Oland, S.; Hieny, S.; Fitzgerald, P.; Oberst, A.; Dillon, C.P.; Green, D.R.; et al. Cutting edge: Endoplasmic reticulum stress licenses macrophages to produce mature IL-1 $\beta$ in response to TLR4 stimulation through a caspase-8- and TRIF-dependent pathway. J. Immunol. 2014, 192, 2029-2033. [CrossRef]

50. Philip, N.H.; DeLaney, A.; Peterson, L.W.; Santos-Marrero, M.; Grier, J.T.; Sun, Y.; Wynosky-Dolfi, M.A.; Zwack, E.E.; Hu, B.; Olsen, T.M.; et al. Activity of Uncleaved Caspase-8 Controls Anti-bacterial Immune Defense and TLR-Induced Cytokine Production Independent of Cell Death. PLoS Pathog. 2016, 12, e1005910. [CrossRef]

51. Nogueira-Machado, J.A.; Volpe, C.M.; Veloso, C.A.; Chaves, M.M. HMGB1, TLR and RAGE: A functional tripod that leads to diabetic inflammation. Expert Opin. Ther. Targets 2011, 15, 1023-1035. [CrossRef] [PubMed]

52. Li, C.; Peng, S.; Liu, X.; Han, C.; Wang, X.; Jin, T.; Liu, S.; Wang, W.; Xie, X.; He, X.; et al. Glycyrrhizin, a Direct HMGB1 Antagonist, Ameliorates Inflammatory Infiltration in a Model of Autoimmune Thyroiditis via Inhibition of TLR2-HMGB1 Signaling. Thyroid 2017, 27, 722-731. [CrossRef] [PubMed]

53. Chi, W.; Chen, H.; Li, F.; Zhu, Y.; Yin, W.; Zhuo, Y. HMGB1 promotes the activation of NLRP3 and caspase-8 inflammasomes via NF-кB pathway in acute glaucoma. J. Neuroinflammation 2015, 12, 137. [CrossRef] [PubMed]

54. Ueta, T.; Ishihara, K.; Notomi, S.; Lee, J.J.; Maidana, D.E.; Efstathiou, N.E.; Murakami, Y.; Hasegawa, E.; Azuma, K.; Toyono, T.; et al. RIP1 kinase mediates angiogenesis by modulating macrophages in experimental neovascularization. Proc. Natl. Acad. Sci. USA 2019, 116, 23705-23713. [CrossRef] [PubMed]

(C) 2020 by the authors. Licensee MDPI, Basel, Switzerland. This article is an open access article distributed under the terms and conditions of the Creative Commons Attribution (CC BY) license (http://creativecommons.org/licenses/by/4.0/). 